\title{
QUESTIONNAIRE ASSESSMENT OF THE WELFARE OF PIGS
}

\author{
G. HORVÁTH* and L. VISNYEI \\ Department of State Veterinary Medicine and Agricultural Economics, Faculty of \\ Veterinary Science, Szent István University, H-1400 Budapest, P.O. Box 2, Hungary
}

(Received April 27, 2000; accepted October 30, 2000)

\begin{abstract}
A questionnaire study was performed involving 76 farms with a total of 380,207 pigs to assess the welfare of pigs kept in Hungary based on the animal welfare legislation of the European Union. Most significant deficiencies were found in the fulfilment of the provisions relating to space requirements, the stall microclimate and the behavioural needs of the animals.
\end{abstract}

Key words: Pigs, welfare assessment, questionnaire survey, legislation

According to a recent review of the problems of large-scale pig farming in Europe (Wittmann and Szücs, 1997), the biggest problems faced by such farms are the meeting of requirements for animal welfare and environmental protection. The present paper sums up the results of a questionnaire study carried out in 1997 to assess the welfare of pigs kept in Hungary based on requirements of the European Union (in the following EU).

Practical assessment of animal welfare is often fraught with difficulties (see e.g. Rushen, 1991). Assessment of whole herds with the methodologies cu rrently used seems even more problematic, since, regardless of the definition used, animal welfare is recognized as an individual characteristic. Therefore, it is questionable whether averaging estimated individual welfare levels would suff iciently characterise a group. Whereas the appraisal of numerous physiological, behavioural and pathological parameters in a representative number of animals on each farm might produce reliable results, it also implies little practicability coupled with considerable costs. Furthermore, even if the welfare assessment of individuals rests upon objective data, the method of expressing their welfare on a continuous numerical scale would need to be used in a standard way. Owing to the lack of a meaningful unit of comparison and the difficulty of determining the relative importance of the welfare-relevant factors, this is a difficult task (Taylor et al., 1995). Similarly, the method of creating an aggregate mean from indivi dual variables had to be standardised as well. Otherwise, the same variables, no matter how objectively measured, could lead to different estimates of animal welfare. This is a key problem with the standardised quantitative models pr o-

*E-mail: ghorvath@univet.hu; Fax: +36 (1) 478-4186 
posed thus far [e.g. the 'Tiergerechtheits-index' of Sundrum et al. (1994) or that of Bartussek (1997)], since these scoring systems do not allow for an interchange of data between them.

An interesting approach has been proposed by Willeberg (1991) who considers disease incidence and prevalence useful in calculating a 'welfare' $p$ arameter. What may be missed, however, with such a health-centred approach, is that health is only one, though an important, component of welfare.

Consequently, one of the preliminaries of our project was to acquire a methodology suitable for the assessment the welfare of pigs on a nation-wide scale. The questionnaire methodology offered an expedient blend of practicabi 1ity and relative ease with which to gather much data cost-effectively in a rel atively short time-span seemed possible. However, these advantages had to be weighed against a possible poor validity of answers. To validate this methodo 1ogy, we performed a pilot study and visited several pig farms.

The questions were based on the provisions of EU Directive 91/630/EEC (Anonymous, 1991) laying down minimum standards for the protection of pigs. Understanding that compliance with these minimum requirements by no means implies optimal welfare, we nevertheless thought that these standards could still be used as a basis for assessment for several reasons. First, the provisions of the directive have been elaborated in order to take account of an array of factors a ffecting the welfare of pigs. Second, it is reasonable to think that where there is not yet full compliance with these minimum requirements, the degree of fulfi 1ment is proportional with the welfare of animals. That is, in the absence of reli ably established relative weights of the different provisions, one could reasonably assume that the more of the requirements are met the better the animals' welfare. Third, for a country such as Hungary, which aspires to membership in the EU, these provisions were deemed to be particularly relevant.

\section{Materials and methods}

\section{Data collection}

The first subset of participants was recruited through advertisements placed in six newspapers targeted primarily at the readership of the countryside in general or at farmers and pig farmers in particular. The second subset of pa rticipants was selected randomly from national breeding registries. A third subset of participants was chosen by official or specialist veterinarians as 'typical' pig units in their area of work. The data collection phase of the study extended from 15 February 1997 to 5 November of the same year. 


\section{Data analysis}

Following thorough scrutiny, the data were entered into a computer. The answers were evaluated according to the following scheme: a value of one was assigned if a provision had been fulfilled whereas a value of zero was assigned if it had not. The data were analysed with a commercial spreadsheet programme using elementary descriptive statistics, i.e. range, sum and mean.

\section{Results}

For the newspaper advertisements, there were six initial respondents of whom finally two returned the completed questionnaire (return rate: 33\%). From the second subset of respondents, only two producers (out of seventy, 3\%) $\mathrm{d}$ eclined co-operation out of hand during the preliminary telephone call because of overworking or because they thought that the method proposed was inadequate ('one would have to come and see'). Of the 70 questionnaires sent, 28 were $\mathrm{r}$ eturned, thus the overall return rate in this subset of responders was $40 \%$. Of the 100 questionnaires distributed among official and specialist veterinarians, 46 were returned. Thus the return rate in this category of responders was about $46 \%$. Taking together all subsets of respondents, the 76 questionnaires returned out of 176 sent correspond to an overall return rate of $43.2 \%$.

The results are summarised in Tables 1 and 2. Table 1 illustrates the mean fulfilment of the general provisions of EU Directive 91/630 whereas Table 2 shows the fulfilment of its specific provisions applying to various categories of pigs (boars, sows and gilts, piglets, weaners and fattening pigs).

\section{Discussion}

The overall return rate in our study was comparable to those obtained by others employing similar methodology (e.g. Chambers et al., 1995; Bennett, 1996; Kent et al., 1996; Hunter et al., 1997; Swanson, 1999). The data of the r eturned questionnaires represent a total of 380,207 animals, corresponding to about $7.5 \%$ of the national herd at the time $(5,035,000$ animals on 1 August 1997). However, with regard to farm size, the distribution of farms in our sample did not correspond to their distribution in Hungary. According to the report of the Hungarian Central Statistical Office (Anonymous, 1997), on 1 December 1997 there were over half a million farmers keeping more than half of the $\mathrm{n}$ ational swine herd with an average farm size of 5 pigs (see Table 3). A more d etailed description of the distribution of the national herd among producers was given by Baltay (1996). From his account it is evident that the majority of pig farmers keep only a couple of animals. These farmers tend to keep pigs in the 
traditional way, their production being more for self-sufficiency rather than to meet the demand of the market.

\section{Table 1}

Mean fulfilment of the general provisions of EU Directive 91/630 and the number of valid responses

\begin{tabular}{|c|c|c|}
\hline Legislative provision & Mean & $\mathrm{N}$ \\
\hline Materials with which the pigs come into contact are - harmless & 0.98 & 75 \\
\hline - easy-to-clean & 0.84 & 76 \\
\hline $\begin{array}{l}\text { - capable of being } \\
\text { disinfected }\end{array}$ & 0.88 & 76 \\
\hline - electrically safe & 0.96 & 76 \\
\hline Appropriate - ventilation & 0.57 & 76 \\
\hline - temperature & 0.43 & 76 \\
\hline - relative humidity & 0.5 & 74 \\
\hline - dust levels & 0.51 & 75 \\
\hline Regular checking of automated mechanical equipment & 0.58 & 46 \\
\hline $\begin{array}{c}\text { Emergency arrangements in case of failure of - automated mechanical } \\
\text { equipment }\end{array}$ & 0.8 & 48 \\
\hline - automated feeding & 0.84 & 25 \\
\hline - automated drinking & 0.87 & 52 \\
\hline - artificial ventilation & 0.83 & 57 \\
\hline Presence of an alarm system if there is artificial ventilation & 0.04 & 50 \\
\hline Regular control of the alarm system (if present) & 0.85 & 10 \\
\hline Appropriate lighting & 0.99 & 74 \\
\hline Ability to inspect the animals any time & 0.98 & 76 \\
\hline Daily checking of the pigs & 0.99 & 76 \\
\hline Procedure with ill or injured animals & 0.99 & 76 \\
\hline Prevention of fighting & 0.63 & 60 \\
\hline Ability of the pigs to - lie down, rest and stand up without difficulty & 0.99 & 73 \\
\hline- have a clean place in which they can rest & 0.94 & 74 \\
\hline - see other pigs & 0.98 & 73 \\
\hline Regular cleaning and disinfection of housing, pens and equipment & 0.97 & 74 \\
\hline Regular removal of faeces, urine, uneaten or spilt food & 0.95 & 74 \\
\hline Floor that is - smooth & 0.82 & 72 \\
\hline- non-slippery & 0.79 & 73 \\
\hline Resting place that is - clean & 0.94 & 74 \\
\hline- dry & 0.93 & 74 \\
\hline - comfortable & 0.74 & 74 \\
\hline Appropriate feed & 0.99 & 74 \\
\hline Daily feeding & 1 & 74 \\
\hline Feeding all animals in a group at the same time & 0.97 & 64 \\
\hline $\begin{array}{l}\text { Access of all pigs over two weeks of age to fresh water or equivalent } \\
\text { fluid }\end{array}$ & 0.96 & 74 \\
\hline Minimal contamination of feeding and watering equipment & 0.47 & 70 \\
\hline Prevention of tail biting and other behavioural anomalies & 0.43 & 62 \\
\hline Access to straw or similar material or object for play and exploration & 0.58 & 74 \\
\hline
\end{tabular}


Table 2

Mean fulfilment of the specific provisions applicable to various categories of pigs of EU Directive $91 / 630$ and the number of valid responses

\begin{tabular}{lcc}
\hline \multicolumn{1}{c}{ Legislative provision } & Mean & N \\
\hline Boars & & \\
Ability of the boars to - turn in their pen & 1 & 74 \\
& - see, hear and smell other pigs \\
$\quad-$ have a clean resting place & 0.99 & 74 \\
Space allowances for boars & 1 & 74 \\
\end{tabular}

Sows/gilts

Absence of tethering

Tethering (if present) not causing any injury

Anti-parasitic treatment of sows and gilts

Proper use of farrowing crates (if used)

Clean, dry and comfortable lying area for sows

Ability of the sows to build a nest

$\begin{array}{lc}0.95 & 71 \\ 0.5 & 4 \\ 0.92 & 73 \\ 0.83 & 73 \\ 0.96 & 73 \\ 0.48 & 73 \\ 0.97 & 73\end{array}$

Sufficient room for natural farrowing

Piglets

Lying area of piglets - that is solid

- that is dry

1

- that is comfortable

$0.99 \quad 73$

- that is away from the sow

$0.91 \quad 73$

- that is warm

$0.56 \quad 72$

- where all piglets can rest at the same time

$0.92 \quad 73$

$0.98 \quad 72$

Proper procedure of castrating piglets (if practised)

$0.88 \quad 73$

Absence of routine tail docking and tooth clipping or evidence on the

$\begin{array}{lll}\text { farm of the negative consequences of not carrying out these procedures } & 0.71 & 73\end{array}$

Absence of weaning before 21 days of age

13

Weaners/fatteners

Space allowance for weaners and fattening pigs - below $10 \mathrm{~kg} \quad 0.96 \quad 68$

- between 10 and $20 \mathrm{~kg} \quad 0.94 \quad 71$

- between 20 and $30 \mathrm{~kg} \quad 0.58 \quad 71$

- between 30 and $50 \mathrm{~kg} \quad 0.97 \quad 71$

- between 50 and $85 \mathrm{~kg} \quad 0.96 \quad 71$

- between 85 and $110 \mathrm{~kg} \quad 0.93 \quad 70$

- above $110 \mathrm{~kg} \quad 0.73 \quad 59$

$\begin{array}{lll}\text { Immediate formation of groups after weaning } & 0.68 & 73\end{array}$

$\begin{array}{lll}\text { Stable group structure } & 0.20 & 73\end{array}$

Due to the large number of small-scale pig farms, average herd size at the time of the study in Hungary was about nine animals per farm (see Table 3). In contrast, average herd size in our study was 5003 animals, which is of the same magnitude as that of enterprises and co-operatives. Based on Baltay's and our 
data, our study represented farms with less than 100, between 100 and 1000 and above 1000 animals per farm to $0,0.8$ and $27.6 \%$, respectively. Consequently, large intensive units were over-represented whereas small-scale traditional far $\mathrm{m}$ ers, among whom the collection of a representative sample with our methodo 1ogy would have been a nearly insurmountable task, were under-represented. As our study extended to about every fourth pig kept on farms with more than 1000 animals (by and large employing an intensive technology), the findings of our study can be extrapolated with confidence to large, intensive units, whereas they do not enable any generalisations to be made with regard to small farms.

Table 3

Distribution of the Hungarian swine population among various types of producers (Anonymous, 1997)

\begin{tabular}{lrcr}
\hline & Number & Number of pigs kept & Mean farm size (pigs) \\
\hline Enterprises & 273 & $1,325,000$ & 4853 \\
Co-operatives & 274 & 960,000 & 3504 \\
Farmers & 529,000 & $2,646,000$ & 5 \\
Total & 529,547 & $4,931,000$ & 9 \\
\hline
\end{tabular}

\section{Fulfilment of general provisions}

The materials used for housing, stalls and equipment were mostly har mless and could be readily cleaned and disinfected, however, problems might arise with worn-out and wooden structures. As the applicable Hungarian legislation contained rules on electrical safety even before the acceptance of the new EU-harmonised legislation, it had not been a problem on most farms.

There were serious problems (also in terms of both production efficiency and animal welfare) with the insulation, heating and ventilation of the buildings. More than half of the farms had problems with inadequate ventilation, temper ature, relative humidity or dust levels at least in some seasons, thereby seriously affecting the profitable operation of the enterprises concerned (Rafai, 1985).

Though an alarm system to warn the stock-keeper of the failure of the art ificial ventilation was installed on only a small fraction of the farms, there was usually sufficient natural ventilation to maintain a satisfactory environment in case of failure. Emergency arrangements in case of failure of other automated and mechanical equipment might also be adequate despite the lack of their reg ular control, since the degree of automation of pig units in Hungary is usually less than it is in most EU member states and thus frequent supervision by stockmen can mitigate the potential harm.

Hungarian pig stalls generally have windows and/or artificial lighting. Therefore keeping pigs permanently in darkness was not normally a problem. 
Also, the pigs could be inspected at any time almost everywhere, which was also commonly done at least once a day. If sick or injured animals were found, ve terinary advice was sought if nece ssary.

Due to lacking or inadequate measures to control aggression among group-housed pigs, fighting caused problems on almost every other farm. Avoi dance of crowding and mixing, supervised regrouping, better environmental co nditions, proper feeding practices, environmental enrichment, etc. could alleviate this problem in many cases and presumably also improve productivity.

The accommodation of pigs usually enabled them to lie down, rest and stand up without difficulty, to have a clean place in which they could rest and to see other pigs. However, the floor (or parts thereof) was either uneven or slippery (or both) on about a quarter of all farms. Bedding could improve these chara cteristics along with comfort, cleanliness and absorption of liquids on the animals' resting place. In many cases, however, this would be incompatible with slatted floors that are prevalent on about three-quarters of the (mainly larger) farms. Cleaning, disinfection and removal of animal waste were generally adequate.

Diet, feeding, and watering were hardly objected, yet the design of feeding and watering equipment could be improved in order to minimise wastage and contamination.

\section{Fulfilment of specific provisions for boars}

Boar stalls allowed the boar to turn round and to hear, smell and see other pigs and they provided clean resting areas on nearly all farms. However, space requirements were fulfilled on only four out of five farms.

\section{Fulfilment of specific provisions for sows and gilts}

Tethering of sows and gilts is not prevalent on Hungarian swine farms. It was encountered on only a few large units with several thousands of pigs and mostly worn-out technology. The tethers used were often uncomfortable, som etimes even causing injury. However, the risk of strangulation was minimal. Pregnant sows and gilts were treated against external and internal parasites on a regular basis or as necessary on nine out of ten farms. They were generally pr ovided with a clean, adequately drained, comfortable lying area. Farrowing crates were used on about two-thirds of the farms examined and they generally also a 1lowed all piglets to be suckled without difficulty. On $30 \%$ of these farms, ho wever, the animals were not cleaned before they were placed into the crate. Though in general there was sufficient space for the ease of natural or assisted farrowing, prior nest building was not possible on more than half of the farms due to the lack of suitable material. Medium-sized and large farms where no fa $\mathrm{r}$ rowing crates were used generally had some means of protecting the piglets (e.g. farrowing rails). Small farms, however, often had no such protection. 


\section{Fulfilment of specific provisions for piglets}

The lying area of the piglets was typically solid, dry and comfortable, of appropriate temperature, where all piglets could rest at the same time. However, it was away from the sow on about every other farm. Most male pigs were ca strated at the age of a few weeks by auxiliary staff or a veterinarian without the use of an anaesthetic. Tail docking and tooth clipping were the routine on the majority of farms. On about half of these, there was no evidence of the cons equences of abandoning these procedures. Mean age of weaning was five weeks, the two extremes being three and eight weeks.

\section{Fulfilment of specific provisions for weaners and fattening pigs}

The overall mean fulfilment of space allowance requirements across all weight categories was $87 \%$. The allowances provided in practice were generally in agreement with the EU requirements except for two categories: first, at the end of the post-weaning period, when the pigs weighing between $20-30 \mathrm{~kg}$ are to be transferred from the battery to the fattening accommodation (there should be a mean increase of about $30 \%$ in the floor area provided here); second, at the end of the fattening phase when the animals have already reached slaughter weight. On two-thirds of the farms, piglets were not immediately regrouped after weaning. Group composition generally changed at least once more (1.23 times on a verage).

Mean fulfilment of all provisions per farm ranged between 0.27 and 0.96 among individual farms. Its mean value across all farms weighted with farm size was 0.75 .

Evaluation of the fulfilment of provisions was obvious in those cases where they were categorically specified in the directive. Such were e.g. the pr ovisions regarding space allowances, various provisions depending on a certain age limit and the prohibition of, or the obligation to carry out, various procedures (in a particular way). In contrast, some provisions were not absolutely explicit. For example, where phrases such as 'appropriate', 'satisfactory', 'sufficient', or 'suitable', or expressions such as 'wherever necessary', 'as necessary', 'if nece ssary' or 'fighting which goes beyond normal behaviour' featured, the provision was subject to interpretation. In these cases, either the stricter interpretation of the provision was applied or the judgement of fulfilment was up to the person filling out the questionnaire (thereby probably also introducing some method ological error). However, the alternative, namely to carry out objective measur ements, would have been far too complicated to be carried out in all cases with good reliability. Presumably this is why the directive did not go into more details in the accurate definition of its provisions either. 


\section{Conclusions}

Overall mean fulfilment of the EU requirements relating to the welfare of intensively kept pigs in our study was about $75 \%$. Save the errors inherent in our methodology, this value is representative of the population of intensively kept pigs on large-scale farms but not of those kept on small farms. Taking into a ccount that the provisions were not directly imposed on Hungarian producers at the time of the study this value may be regarded quite high. In contrast, consi dering that some provisions were indirectly binding (in case of EU export), were also contained in the applicable Hungarian legislation or in technological sta ndards, were well established scientifically or were simply common sense, this value may appear relatively low.

One of the main problem areas appears to be the fulfilment of the beha vioural needs of the animals about which either stockmen know little (perhaps u naware of their natural behaviour, they may have got accustomed to the types of behaviour shown by the animals on the particular farm assuming that this would be the norm) or they are not willing or able to put this knowledge into practice. This concerns the formation of groups and the prevention of fighting, the access to straw or other suitable material or object for play, exploration or, in case of preparturient animals, nest building. Even though the provisions relating to these behavioural needs are not explicitly compulsory owing to the inclusion of qual ifying phrases, their fulfilment would improve the well-being and in many cases also the productivity of the animals. Hence the often minimal investment and o perational costs seem negligible in relation to the potential benefits. In some cases, compliance could be achieved through organisational measures. For example, spatial requirements could be met by decreasing group size by one or two an imals or moving the group to their new accommodation earlier. Of course, this would mean higher building cost per animal but the producer would not need to invest large sums of money in the short term in order to meet legislative $\mathrm{r}$ equirements. Furthermore these costs could be countered by decreased losses due to disease, aggression, etc. Another significant problem area is the stall micr oclimate in the correction of which investment is inevitable. However, its costs may be reduced if producers know about, and make preparations well in advance for, the necessary future technological changes.

\section{Acknowledgements}

The authors would like to thank the farmers and veterinary surgeons who assisted with this study. 


\section{References}

Anonymous (1991): Council Directive of 19 November 1991 laying down minimum standards for the protection of pigs $(91 / 630 / \mathrm{EEC})$.

Anonymous (1997): Report of the Hungarian Central Statistical Office on the cattle and pig stock on 1 December 1997 (in Hungarian). pp. 8, 12, 18 .

Baltay, M. (1996): It is about money... (in Hungarian). A Sertés 1, 4-6.

Bartussek, H. (1997): Practical experience in the application of the animal welfare index 'TGI 35L' in Austria. 23. IGN-Meeting: Welfare-friendly housing systems for farm animals (in German). 23-25 October 1997, Tänikon, Switzerland.

Bennett, R. M. (1996): Willingness-to-pay measures of public support for farm animal welfare legislation. Vet. Rec. 139, 320-321.

Chambers, C., Powell, L., Wilson, E. and Green, L. E. (1995): A postal survey of tail biting in pigs in south west England. Vet. Rec. 136, 147-148.

Hunter, E. J., Riches, H. L., Guise, H. J. and Penny, R. H. C. (1997): The behaviour of pigs in lairage in relation to their post-weaning management: results of a postal survey. Anim. Welfare 6, 139-144.

Kent, J. E., Thrusfield, M. V., Robertson, I. S. and Molony, V. (1996): Castration of calves: a study of methods used by farmers in the United Kingdom. Vet. Rec. 138, 384-387.

Rafai, P. (1985): Microclimate demands in large-scale pig husbandry (in Hungarian, with English abstract). Magyar Állatorvosok Lapja 40, 651-654.

Rushen, J. (1991): Problems associated with the interpretation of physiological data in the assessment of animal welfare. Appl. Anim. Behav. Sci. 28, 381-386.

Sundrum, A., Andersson, R. and Postler, G. (eds) (1994): Animal Welfare Index 200/1994. Guiding Principles for the Evaluation of Housing Systems (in German). Köllen-Verlag, Bonn.

Swanson, J. C. (1999): What are animal science departments doing to address contemporary issues? J. Anim. Sci. 77, 354-360.

Taylor, A. A., Hurnik, J. F. and Lehmann, H. (1995): The application of cost-benefit dominance analysis to the assessment of farm animal quality of life. Soc. Ind. Res. 35, 313-329.

Willeberg, P. (1991): Animal welfare studies: epidemiological considerations. In: Thrusfield, M. V. (ed.) Proceedings of a meeting of the Society for Veterinary Epidemiology and Preventive Medicine held at the University of London on 17-19th of April 1991. xi +144 pp. Society for Veterinary Epidemiology and Preventive Medicine, Roslin, Midlothian EH25 9RG, UK.

Wittmann, M. and Szűcs, E. (1997): Report on the problems of the large scale pig farms in Europe. Pig News Inf. 1997, 18, 87N-90N. 